\title{
Preservation of Olfaction after Unilateral Endoscopic Approach for Resection of Esthesioneuroblastoma
}

\author{
Aaron Wessell ${ }^{1}$ Ameet Singh ${ }^{2}$ Zachary Litvack ${ }^{3}$ \\ ${ }^{1}$ School of Medicine, The George Washington University Medical \\ Center, Washington, District of Columbia, United States \\ 2 Department of Surgery, Division of Otolaryngology, The George \\ Washington University Medical Center, Washington, District of \\ Columbia, United States \\ ${ }^{3}$ Department of Neurosurgery, The George Washington University \\ Medical Center, Washington, District of Columbia, United States
}

\begin{abstract}
Address for correspondence Zachary Litvack, MD, MCR, Co-Director, Endoscopic Pituitary and Anterior Skull-Base Surgery Program, Department of Neurosurgery, George Washington University Medical Center, 2150 Pennsylvania Avenue, NW, Suite 7-420, Washington, DC 20037, United States (e-mail: zlitvack@mfa.gwu.edu).
\end{abstract}

J Neurol Surg Rep 2014;75:e149-e153.

\begin{abstract}
Keywords

- endoscopy

- esthesioneuroblastoma

- skull-base

- olfactory preservation

- craniofacial

Objectives We present a case of olfactory preservation after a unilateral transcribriform transethmoidal endoscopic resection of esthesioneuroblastoma. We also discuss the oncologic results of endoscopic and transcranial approaches and describe the potential benefits and limitations of an endoscopic approach.

Setting Single academic medical center.

Participant and Design The clinical course of a 28-year-old patient who underwent endoscopic en bloc resection of esthesioneuroblastoma through a unilateral transcribriform transethmoidal approach was reviewed.

Results Imaging demonstrated a left-sided nasal mass with cribriform plate involvement (Kadish C). Intraoperatively, the left olfactory bulb and epithelium were sacrificed. Negative frozen sections were obtained from the right olfactory epithelium and dura surrounding the right olfactory bulb. Reconstruction was performed using a multilayered closure of fascia, rigid buttress, and nasoseptal flap. Histology was consistent with esthesioneuroblastoma. Postoperative clinical evaluation, endoscopy, and magnetic resonance imaging demonstrated no evidence of residual or recurrent tumor at 18 months. The UPSIT smell testing revealed normal olfaction preoperatively, moderate microsomia at 3 months postoperatively, and mild microsomia at 18 months postoperatively.

Conclusions Endoscopic resection of esthesioneuroblastoma has demonstrated similar oncologic control while reducing postoperative morbidity and mortality over transcranial approaches. This case reveals the potential to preserve olfaction while achieving en bloc endoscopic resection of early stage esthesioneuroblastoma.
\end{abstract}

\section{Introduction}

Esthesioneuroblastoma (ENB), also known as olfactory neuroblastoma, is a rare malignant tumor of neuroectodermal origin arising from the olfactory epithelium. These tumors are often unilateral slow-growing masses presenting in the orbital rim or ethmoid sinuses. ENB comprises 1 to $5 \%$ of intranasal tumors ${ }^{1-4}$ and represents $<1 \%$ of all malignant received

January 29, 2014

accepted

April 3, 2014

published online

June 24, 2014
DOI http://dx.doi.org/

10.1055/s-0034-1376427. ISSN 2193-6358. (c) 2014 Georg Thieme Verlag KG
Stuttgart · New York

License terms

(1) $\Theta \circledast$ 

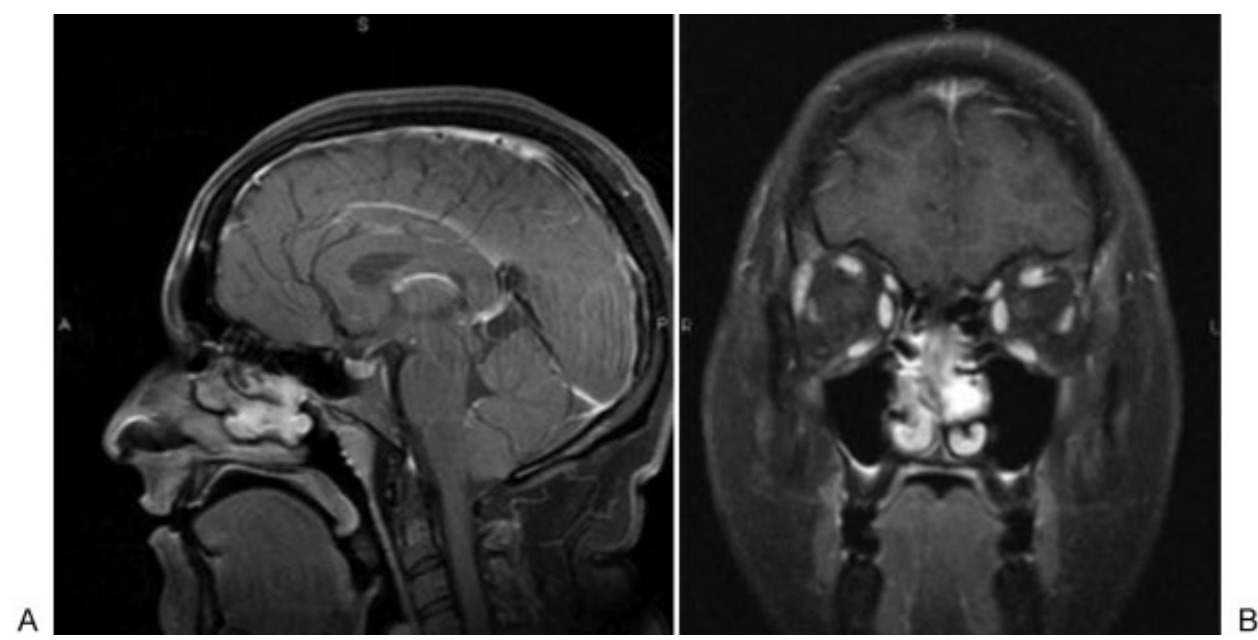

Fig. 1 Preoperative (A) sagittal and (B) coronal T1-weighted postcontrast magnetic resonance imaging demonstrating a $2.8 \times 2.2 \times 1 \mathrm{~cm}$ enhancing soft tissue lesion in the left nasal cavity located medial and inferior to the middle turbinate.

tumors. ${ }^{5}$ Diagnosis of ENB tends to occur late in the disease course, most commonly presenting in the second and fifth decades of life as unilateral nasal obstruction and epistaxis. ${ }^{6-8}$ Other presenting symptoms reported in the literature include headache, cheek fullness, proptosis, epiphora, retrobulbar pain, vision changes, infraorbital neuralgia, cranial nerve deficits, olfactory dysfunction, altered mental status, nausea, vomiting, and neuroendocrine abnormalities. ${ }^{9-11}$

Traditional first-line treatment for ENB is craniofacial resection (CFR) with postoperative radiation therapy. The goal of surgery is to achieve a gross total resection with histologically negative margins. Although the importance of radiation and chemotherapy remains controversial in the literature, ${ }^{12,13}$ surgical treatment in combination with adjuvant radiation and/or chemotherapy has undeniably improved outcomes since the first description of ENB in the literature in $1924.8,12,14,15$ More recently, the purely endoscopic endonasal approach (EEA) has increased in popularity, proving to be an effective method for ENB resection. This technique offers the benefits of reduced morbidity and mortality compared with traditional CFR while achieving comparable oncologic results. ${ }^{13-16}$ Although critics argue that the endoscopic technique limits the ability to achieve a complete en bloc resection, a partial or unilateral resection may be appropriate in select cases. Here we describe a case of olfactory preservation after a unilateral transcribriform transethmoidal resection of ENB.

\section{Clinical Presentation}

A 28-year-old woman presented to the outpatient otolaryngology clinic complaining of chronic bilateral nasal congestion. Direct endoscopic visualization revealed a left-sided mass of the sphenoethmoid recess. Magnetic resonance imaging (MRI) demonstrated a $2.8 \times 2.2 \times 1.0 \mathrm{~cm}$ contrastenhancing soft tissue lesion in the left nasal cavity with erosion of the cribriform plate ( - Fig. 1). Preoperative histology was consistent with ENB. Preoperative University of
Pennsylvania Smell Identification Test (UPSIT) ${ }^{16}$ revealed normal olfaction.

The patient underwent EEA resection via a unilateral transcribriform transethmoidal approach. The olfactory apparatus (epithelium, cribriform plate, and olfactory bulb) was removed en bloc with the tumor, sectioning the olfactory tract $1 \mathrm{~cm}$ posterior to the tumor margin ( $\mathbf{F i g . ~ 2 ) . ~ T h i s ~}$ spared the right olfactory apparatus. Intraoperative frozen pathologic sections (ipsilateral olfactory tract, contralateral olfactory epithelium, cribriform dura and bulb) were obtained to confirm histologically negative surgical margins. A multilayered closure was performed using fascia, rigid

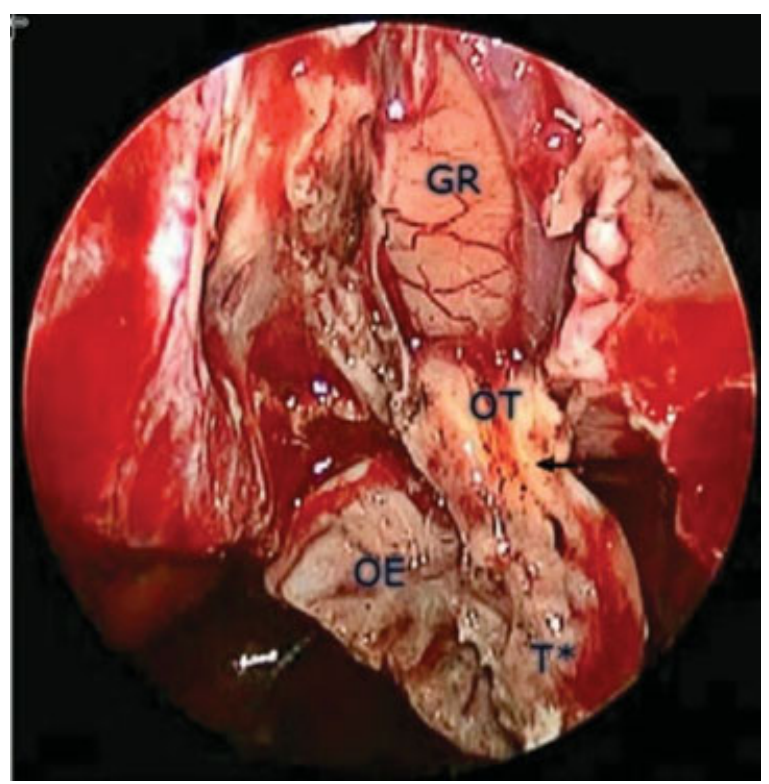

Fig. 2 Intraoperative endoscopic image, left nasal cavity, demonstrating en bloc dissection of the olfactory apparatus prior to resection. The transition from tumor to normal olfactory tract is evident (arrow). GR, gyrus rectus; OE, olfactory epithelium; OT, olfactory tract; $\mathrm{T}^{*}$, tumor. 

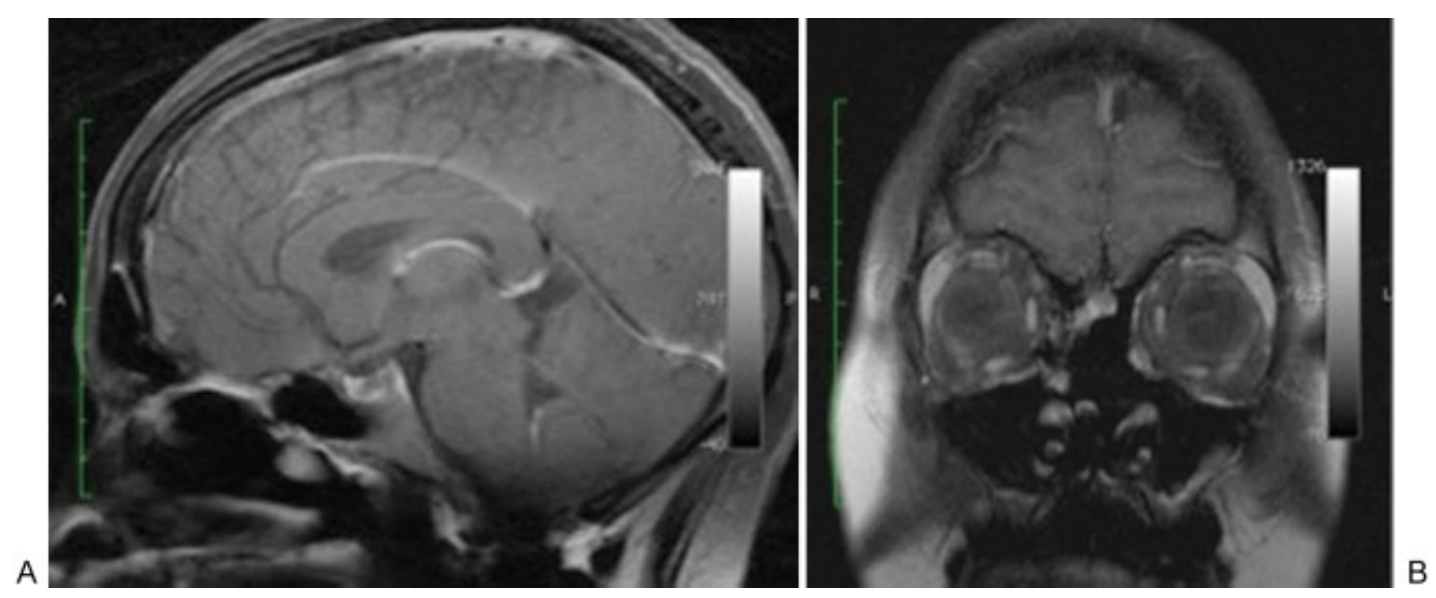

Fig. 3 (A) Sagittal and (B) coronal T1-weighted postcontrast magnetic resonance imaging at 18 months postoperatively showing resection of the bony nasal septum, portions of the middle nasal turbinates, ethmoidal air cells, and the medial wall of the left maxillary antrum. No evidence of tumor recurrence is visible.

buttress, and a vascularized nasoseptal flap with fibrin-based tissue sealant. No intraoperative complications were encountered. Postoperatively, the patient experienced a vigorous aseptic meningitis requiring high-dose steroid therapy for 7 days.

Immediate postoperative MRI revealed no evidence of residual tumor, and no adjuvant radiation therapy was prescribed. The patient was maintained on a regimen of nasal hygiene with twice daily nasal saline spray and routine rhinologic follow-up. Nasal debridement occurred on an asneeded basis at 10 days and 3 weeks postoperatively. UPSIT smell testing ${ }^{17}$ revealed moderate microsomia at 3 months postoperatively and mild microsomia at 18 months postoperatively. The patient remained disease free at last follow-up of 18 months (-Fig. 3).

\section{Discussion}

ENB is a rare malignancy with 5- and 10-year survival rates of $\sim 80 \%$ and $50 \%$, respectively. ${ }^{3,17-20}$ Metastasis is reported at the time of diagnosis in 10 to $33 \%$ of cases. ${ }^{6,7,21-24}$ Despite high rates of cervical metastases, with adequate treatment, ENB carries a superior prognosis compared with other superior nasal malignancies. ${ }^{25}$ First-line treatment for ENB is CFR with postoperative radiation therapy, combining a bifrontal craniotomy and transfacial approach to achieve true en bloc resection. This technique is associated with high morbidity and mortality ranging from $30 \%$ to $50 \%{ }^{26,27}$ Potential complications reported in the literature include intracranial hypertension, cerebrovascular accident, pneumocephalus, cerebrospinal fluid (CSF) leak, orbital complications, cosmetic complications, infection, and various systemic complications. ${ }^{17}$ More aggressive approaches have been reported, using neoadjuvant concomitant radiation and platinumbased chemotherapy with limited success. ${ }^{28}$

Endoscopic-assisted CFR was first described in the 1990s, combining a bifrontal craniotomy with an endoscopic endonasal approach, for ENB resection. ${ }^{29-31}$ More recently, purely EEA techniques have been used. The benefits of an endoscopic approach include superior visualization, decreased operative time, reduced length of hospital stay, less postoperative pain, and avoidance of craniotomy and facial incision. The literature contains numerous reports of EEA ENB resection, with oncologic results comparable with that of traditional CFR. ${ }^{21,29,32,33}$

In 1999, Stammeberger et al performed a retrospective review of eight EEA ENB resections, with gamma knife adjuvant therapy used in select cases. All patients were found to be alive and disease free after a mean follow-up period of 37.2 months. ${ }^{32}$ Castelnuovo reported similar findings with nearly all patients remaining disease free at 38.1 months, demonstrating that a purely EEA approach can achieve histologically negative surgical margins. Of note, among this select group of patients, 90\% received adjuvant radiation therapy and one patient received chemotherapy due to advanced disease. ${ }^{34}$ Casiano et al support these findings with $80 \%$ of patients remaining free of disease at 31 months postoperatively. ${ }^{29}$ Several retrospective studies describe similar experiences with the EEA approach, some involving late stage tumors. ${ }^{8,29}$ The shorter follow-up times in the EEA studies relative to CFR studies limits comparison of these two approaches. Thorough evaluation of ENB resection techniques requires long-term follow-up because recurrence and metastases have been reported up to 10 years after initial treatment. ${ }^{35}$

To date, a handful of investigators have developed ENB classification schemes aimed at guiding surgical therapy and demonstrating varying degrees of prognostic significance. $^{12,23,36,37}$ The Kadish system, in particular, has been shown to have prognostic significance for recurrence and 2and 5-year survival rates. The Kadish system classifies tumors as follows: Kadish stage A tumors are limited to the nasal cavity, and Kadish extend into the paranasal sinuses and stage $\mathrm{C}$ beyond the paranasal sinuses. Kadish stages $\mathrm{A}$ and $\mathrm{B}$ have lower rates of recurrence and increased survival compared with Kadish stage $C^{23}$

In 2009, a meta-analysis published by Devaiah et al compared the results for open and endoscopic ENB resection in 361 patients. Endoscopic surgery was found to improve survival rates significantly compared with open surgery with 
no significant difference in follow-up time between groups. Notably, patients in the open surgical group possessed more complex tumors. A total of $63 \%$ of all open cases consisted of Kadish stages C and D tumors; $56 \%$ of endoscopic and $61 \%$ of endoscopically assisted cases were Kadish stages A and B. ${ }^{33}$

More recently, Komotar et al performed a thorough literature review comparing EEA with CFR and combined open/ endonasal (CN) ENB resection. The study population consisted of 47 studies with 453 patients divided into three cohorts based on the respective surgical approach: CFR $(n=318)$, EEA $(n=102)$, and $\mathrm{CN}(n=33)$. The study revealed a greater rate of gross total resection for EEA cases (98.1\%) compared with CFR (81.3\%). Negative surgical margins were achieved in $93.8 \%, 95.8 \%$, and $77.3 \%$ of EEA, $C N$, and CFR cases, respectively. The EEA approach was also associated with a decreased rate of regional metastases and greater survival at last follow-up. These findings support the notion that purely EEA or CN approaches do not result in significantly worse surgical and oncologic outcomes compared with traditional CFR, and they serve as viable alternatives for surgical resection. ${ }^{38}$ However, much like the meta-analysis published by Devaiah and colleagues, one must consider the fact that high-grade tumors (Kadish stage C) are frequently treated with open surgical approaches, whereas endoscopic techniques are more often used for lower grade tumors (Kadish stages $\mathrm{A}$ and $\mathrm{B}){ }^{33}$

Despite the proven utility and benefits of a purely EEA, this technique is not without complication. Historically, postoperative CSF leak has been a concern with ENB, particularly when dural involvement is present. ${ }^{39,40}$ Fortunately, newly developed endoscopic skull base reconstruction techniques have proven to be very effective. A new multilayered closure technique, called the gasket seal, has been used in combination with a vascularized nasoseptal flap for a variety of anterior skull base lesions with zero incidence of CSF leak in select studies. ${ }^{41}$ Other potential complications reported in the literature include intraoperative bleeding, orbital hematoma, frontal lobe abscess, epistaxis, and prolonged nasal crusting. ${ }^{42}$

Most patients are able to undergo endoscopic resection safely and successfully in the hands of an experienced team of endoscopic neurosurgeons and otolaryngologists. However, patients frequently complain of prolonged nasal crusting during the postoperative period. In a quality of life analysis, $69 \%$ and $61 \%$ of skull base surgery patients complained of smell disturbance and nasal crusting, respectively. ${ }^{43}$ Given the intimate relationship of ENB with the cribriform plate and olfactory nerves, olfactory function is often compromised, both from resection of olfactory epithelium and postoperative radiation-induced atrophic rhinitis. However, olfactory dysfunction can be reduced with the EEA approach relative to traditional CFR. ${ }^{38}$ Castelnuovo et al demonstrate that olfactory preservation is possible with EEA approach for en bloc or piecemeal resection. ${ }^{34}$ Critics of the endoscopic approach argue that this technique limits the ability to achieve en bloc resection, negatively impacting the rate of oncologic cure. However, one may make the claim that in the hands of an experienced endoscopic surgeon, there is little, if any, difference in the degree of tissue removed via the endoscopic approach compared with CFR. Moreover, the literature supports the notion that piecemeal resection does not necessarily translate to an increased rate of local recurrence. ${ }^{21,31,44}$

This case provides further support that olfactory preservation is possible via an EEA in select cases of ENB. Olfactory preservation should be considered as an end objective, particularly in patients with low-grade tumors (Kadish stages A and B) and unilateral disease. Meticulous preoperative planning is necessary for olfactory preservation while achieving a sound oncologic resection. Preoperative MRI and axial and coronal computed tomography imaging must be reviewed to assess the extent of soft tissue invasion and bony erosion. The limitations of the EEA must be taken into consideration as well. For more extensive lesions that invade laterally into the maxillary sinus, pterygomaxillary fissure, or infratemporal fossa, and lesions that involve the soft tissues of the face, traditional CFR may be indicated. Adjuvant radiation therapy can be used in select cases to increase local control..$^{3,13,34,45,46}$ Follow-up care with a rhinologist is necessary to ensure proper wound healing. Additionally, long-term follow-up with direct endoscopic visualization and MRI imaging is advised, regardless of surgical technique, to monitor for local recurrence and metastasis.

\section{Conclusion}

Endoscopic endonasal resection of ENB has demonstrated similar oncologic control while reducing postoperative morbidity and mortality over traditional transcranial approaches. This case illustrates the potential to preserve olfaction following en bloc resection of ENB. Further evaluation of surgical technique is required to improve preservation while ensuring adequate oncologic resection. Futures studies must incorporate long-term follow up to adequately assess the rate of oncologic cure compared with traditional approaches.

\section{Disclosures}

The authors have no financial or materials support to disclose.

\section{References}

1 Broich G, Pagliari A, Ottaviani F. Esthesioneuroblastoma: a general review of the cases published since the discovery of the tumour in 1924. Anticancer Res 1997;17; A2683-2706

2 Irish J, Dasgupta R, Freeman J, et al. Outcome and analysis of the surgical management of esthesioneuroblastoma. J Otolaryngol 1997;26(1):1-7

3 Foote RL, Morita A, Ebersold MJ, et al. Esthesioneuroblastoma: the role of adjuvant radiation therapy. Int J Radiat Oncol Biol Phys 1993;27(4):835-842

4 Beitler JJ, Fass DE, Brenner HA, et al. Esthesioneuroblastoma: is there a role for elective neck treatment? Head Neck 1991;13(4):321-326

5 Svane-Knudsen V, Jørgensen KE, Hansen O, Lindgren A, Marker P. Cancer of the nasal cavity and paranasal sinuses: a series of 115 patients. Rhinology 1998;36(1):12-14

6 Elkon D, Hightower SI, Lim ML, Cantrell RW, Constable WC. Esthesioneuroblastoma. Cancer 1979;44(3):1087-1094

7 Spaulding CA, Kranyak MS, Constable WC, Stewart FM. Esthesioneuroblastoma: a comparison of two treatment eras. Int J Radiat Oncol Biol Phys 1988;15(3):581-590 
8 Walch C, Stammberger H, Anderhuber W, Unger F, Köle W, Feichtinger $\mathrm{K}$. The minimally invasive approach to olfactory neuroblastoma: combined endoscopic and stereotactic treatment. Laryngoscope 2000;110(4):635-640

9 Levine PA, McLean WC, Cantrell RW. Esthesioneuroblastoma: the University of Virginia experience 1960-1985. Laryngoscope 1986; 96(7):742-746

10 Koka VN, Julieron M, Bourhis J, et al. Aesthesioneuroblastoma. J Laryngol Otol 1998;112(7):628-633

11 Lund VJ, Milroy C. Olfactory neuroblastoma: clinical and pathological aspects. Rhinology 1993;31(1):1-6

12 Biller HF, Lawson W, Sachdev VP, Som P. Esthesioneuroblastoma: surgical treatment without radiation. Laryngoscope 1990; 100(11):1199-1201

13 Morita A, Ebersold MJ, Olsen KD, Foote RL, Lewis JE, Quast LM. Esthesioneuroblastoma: prognosis and management. Neurosurgery 1993;32(5):706-714; discussion 714-715

14 Berger L, Luc H, Richard R. L'esthesioneuro epitheliome olfactif. Bull Assoc Fr Etud Cancer 1924;13:410-420

15 Dulguerov P, Calcaterra T. Esthesioneuroblastoma: the UCLA experience 1970-1990. Laryngoscope 1992;102(8):843-849

16 Doty RL, Shaman P, Kimmelman CP, Dann MS. University of Pennsylvania Smell Identification Test: a rapid quantitative olfactory function test for the clinic. Laryngoscope 1984;94(2 Pt 1): 176-178

17 Levine PA, Gallagher R, Cantrell RW. Esthesioneuroblastoma: reflections of a 21-year experience. Laryngoscope 1999;109(10): 1539-1543

18 Shah JP, Kraus DH, Bilsky MH, Gutin PH, Harrison LH, Strong EW. Craniofacial resection for malignant tumors involving the anterior skull base. Arch Otolaryngol Head Neck Surg 1997;123(12): 1312-1317

19 Levine PA, Debo RF, Meredith SD, Jane JA, Constable WC, Cantrell RW. Craniofacial resection at the University of Virginia (19761992): survival analysis. Head Neck 1994;16(6):574-577

20 Spiro JD, Soo KC, Spiro RH. Nonsquamous cell malignant neoplasms of the nasal cavities and paranasal sinuses. Head Neck 1995;17(2):114-118

21 Batra PS, Citardi MJ, Worley S, Lee J, Lanza DC. Resection of anterior skull base tumors: comparison of combined traditional and endoscopic techniques. Am J Rhinol 2005;19(5):521-528

22 Skolnik EM, Massari FS, Tenta LT. Olfactory neuroepithelioma. Review of the world literature and presentation of two cases. Arch Otolaryngol 1966;84(6):644-653

23 Kadish S, Goodman M, Wang CC. Olfactory neuroblastoma. A clinical analysis of 17 cases. Cancer 1976;37(3):1571-1576

24 Eden BV, Debo RF, Larner JM, et al. Esthesioneuroblastoma: longterm outcome and patterns of failure-the University of Virginia experience 1960-1985. Laryngoscope 1994;((96):742-746

25 Davis RE, Weissler MC. Esthesioneuroblastoma and neck metastasis. Head Neck 1992;14(6):477-482

26 Kraus DH, Shah JP, Arbit E, Galicich JH, Strong EW. Complications of craniofacial resection for tumors involving the anterior skull base. Head Neck 1994;16(4):307-312

27 Richtsmeier WJ, Briggs RJ, Koch WM, et al. Complications and early outcome of anterior craniofacial resection. Arch Otolaryngol Head Neck Surg 1992;118(9):913-917
28 Sohrabi S, Drabick JJ, Crist H, Goldenberg D, Sheehan JM, Mackley HB. Neoadjuvant concurrent chemoradiation for advanced esthesioneuroblastoma: a case series and review of the literature. J Clin Oncol 2011;29(13):e358-e361

29 Casiano RR, Numa WA, Falquez AM. Endoscopic resection of esthesioneuroblastoma. Am J Rhinol 2001;15(4):271-279

30 Yuen AP, Fan YW, Fung CF, Hung KN. Endoscopic-assisted cranionasal resection of olfactory neuroblastoma. Head Neck 2005; 27(6):488-493

31 Thaler ER, Kotapka M, Lanza DC, Kennedy DW. Endoscopically assisted anterior cranial skull base resection of sinonasal tumors. Am J Rhinol 1999;13(4):303-310

32 Stammberger H, Anderhuber W, Walch C, Papaefthymiou G. Possibilities and limitations of endoscopic management of nasal and paranasal sinus malignancies. Acta Otorhinolaryngol Belg 1999;53(3):199-205

33 Devaiah AK, Andreoli MT. Treatment of esthesioneuroblastoma: a 16-year meta-analysis of 361 patients. Laryngoscope 2009; 119(7):1412-1416

34 Castelnuovo PG, Delù G, Sberze F, et al. Esthesioneuroblastoma: endonasal endoscopic treatment. Skull Base 2006;16(1):25-30

35 Loy AH, Reibel JF, Read PW, et al. Esthesioneuroblastoma: continued follow-up of a single institution's experience. Arch Otolaryngol Head Neck Surg 2006;132(2):134-138

36 Resto VA, Eisele DW, Forastiere A, Zahurak M, Lee DJ, Westra WH. Esthesioneuroblastoma: the Johns Hopkins experience. Head Neck 2000;22(6):550-558

37 Polin RS, Sheehan JP, Chenelle AG, et al. The role of preoperative adjuvant treatment in the management of esthesioneuroblastoma: the University of Virginia experience. Neurosurgery 1998; 42(5):1029-1037

38 Komotar RJ, Starke RM, Raper DM, Anand VK, Schwartz TH. Endoscopic endonasal compared with anterior craniofacial and combined cranionasal resection of esthesioneuroblastomas. World Neurosurg 2013;80(1-2):148-159

39 Poetker DM, Toohill RJ, Loehrl TA, Smith TL. Endoscopic management of sinonasal tumors: a preliminary report. Am J Rhinol 2005; 19(3):307-315

40 Folbe A, Herzallah I, Duvvuri U, et al. Endoscopic endonasal resection of esthesioneuroblastoma: a multicenter study. Am J Rhinol Allergy 2009;23(1):91-94

41 Leng LZ, Brown S, Anand VK, Schwartz TH. "Gasket-seal” watertight closure in minimal-access endoscopic cranial base surgery. Neurosurgery 2008; 62(5, Suppl 2):E342-E343; discussion E343

42 Dave SP, Bared A, Casiano RR. Surgical outcomes and safety of transnasal endoscopic resection for anterior skull tumors. Otolaryngol Head Neck Surg 2007;136(6):920-927

43 Palme CE, Irish JC, Gullane PJ, Katz MR, Devins GM, Bachar G. Quality of life analysis in patients with anterior skull base neoplasms. Head Neck 2009;31(10):1326-1334

44 Har-El G, Casiano RR. Endoscopic management of anterior skull base tumors. Otolaryngol Clin North Am 2005;38(1):133-144, ix

45 Diaz EM Jr, Johnigan RH III, Pero C, et al. Olfactory neuroblastoma: the 22-year experience at one comprehensive cancer center. Head Neck 2005;27(2):138-149

46 O'Connor TA, McLean P, Juillard GJF, Parker RG. Olfactory neuroblastoma. Cancer 1989;63(12):2426-2428 